\title{
TEROTEHNOLOŠKI ASPEKTI U EKSPLOATACIJI I ODRŽAVANJU VRELOVODNOG KOTLA TIP ERK- RHW 30
}

\author{
Dr Sanja Marković \\ Visoka poslovna škola strukovnih studija „Prof. dr Radomir Bojković“ Kruševac \\ e-mail: teodorasanja@gmail.com

\section{Dr Spomenka Gligorijević} \\ Visoka poslovna škola strukovnih studija „Prof. dr Radomir Bojkovićc Kruševac \\ e-mail: glispom@gmail.com
}

\section{Sažetak}

Tokom eksploatacije vrelovodnog membranskog strmog kotla ERK-RH3O kapaciteta $30 \mathrm{MW}$, koji se nalazi u okviru termoeneretskog postrojenja JKP "Toplana Valjevo", izvršen je vizuelni pregled $i$ napravljen fotografski zapis postrojenja na kojem su zapažene povećane naslage (depoziti) kao $i$ povećano prisustvo kondenzacije, ovlaženih zona i korozije. Da bi kotlovsko postrojenje radilo prema zadatom režimu neophodno je primeniti sve raspoložive, propisane i zadate mere održavanja. U radu su prikazane terotehnološke aktivnosti grupisane prema izvoru finansiranja i prema vremenu u odnosu na nastalu neispravnost kotlovskog postrojenja.

\section{Abstract}

During the operation of hot water boiler membrane steep ERK-RH3O with capacity of $30 \mathrm{MW}$, located in the thermo energy plant PC "Heating plant Valjevo", a visual examination and photographic record of facility were made, in which significantly more deposits were perceived, as well as the increased presence of condensation, wetted zone and corrosion. It was necessary to apply all available, correct and required maintenance measures, so that power station would be in regime. The paper presents terotechnological activities grouped by source of funding and the time in relation to the resulting failure of the boiler plant

Ključne reči: vrelovodni kotao, depozit, oštećenje, korozija, održavanje

Keywords: hot water boiler, deposit, damage, corrosion, maintenance

\section{Uvod}

Parni kotao je deo kompleksnog energetskog, procesnog ili toplotnog sistema u kom se hemijska energija goriva transformiše $u$ energiju vodene pare. Kotlovi mogu biti:

- parni.

- toplovodni

- vrelovodni

Prema konstrukciji, vrelovodni kotlovi se mogu podeliti na:

- Kotlove sa plamenom cevi i dimnim cevima

- Kotlove sa vodogrejnim cevima, a oni na:

a) kotlove sa vodogrejnim cevima bez doboša

b)kotlove sa vodogrejnim cevima sa dobošem 
Osnovna prednost kotlova sa plamenom cevi i dimnim cevima je da im je temperatura vode ujednačena i da mogu da budu završeni potpuno u fabrici i isporučeni kao tzv. "blok kotlovi". Blok kotlovi se proizvode kao: generatori zasićene ili pregrejane pare, generatori toplote $\mathrm{i}$ vrele vode za zatvorene $\mathrm{i}$ otvorene sisteme, potpuno automatski za sagorevanje lakog ili teškog ložnog ulja, raznih gasova, kao i raznih otpadaka, kotlovi sa ekranisanom zadnjom komorom, kotlovi sa dve plamene cevi. U pogledu cirkulacionih tokova i mešanja vode može se usvojiti da u kotlu vlada srednja temperatura koja je približno jednaka aritmetičkoj sredini temperature vode na ulazu i izlazu. Osnovni nedostaci kotlova ovog tipa su:

- relativno ograničeni kapacitet i pritisak

- zaprljanost sa vodene strane može da dovede do ozbiljnih havarija, jer u slučaju stvaranja kamenca ili taloženja ulja, bitno raste temperatura plamene cevi i dimnih cevi u odnosu na temperaturu cilindričnog omotača, pa nastala razlika u dilatacijama može da dovede do pucanja ravnih cevnih zidova. [4]

Oštećenja koja se javljaju kod kotlovskih postrojenja mogu da budu posledica delovanja različitih mehanizama, pri čemu postoje i situacije kada više mehanizama deluje istovremeno. Da bi se dobila što realnija slika o stanju materijala kotlovskog postrojenja, odnosno da bi se što realnije procenio životni vek i pouzdanost postrojenja, neophodno je svako postrojenje i njegove komponente posmatrati nezavisno, obzirom da pojava oštećenja zavisi pre svega od faktora koji su karakteristični za dato postrojenje - konstrukcija, karakteristike postrojenja, vrsta goriva i njegove karakteristike, radni parametri (neujednačenost kvaliteta goriva, broj startovanja, vreme neprekidnog rada), itd. Zbog različitog životnog veka i pouzdanosti, neke elemente postrojenja treba menjati ranije odnosno više puta u životnom veku, zavisno od odnosa trajanja životnog veka, pouzdanosti elemenata i uslova eksploatacije. Kada je reč o kotlovskim postrojenjima, u najvećem broju slučajeva razaranje komponenti se odvija postepeno. Obzirom da je veoma teško uočiti početne stadijume oštećenja a samim tim i razaranja, nije moguće sprovesti bilo kakvu akciju u okviru preventivnog održavanja, kojom bi se sprečilo širenje oštećenja. Posle izvesnog vremena kada je oštećenje već vidljivo neophodno je primeniti mere održavanja pre nego što dođe do loma.

\section{Osnovni tehnički podaci o kotlovskom postrojenju}

U okviru termoeneretskog postrojenja JKP "Toplana Valjevo" nalazi se vrelovodni membranski strmi kotao ERK-RH30 kapaciteta 30 MW, koji se koristi za proizvodnju vrele vode zagrevanjem instalacija za grejanje objekata korisnika daljinskog grejanja, distribucijom fluida preko vrelovoda i podstanica. Proizvođač kotlovskog postrojenja je „REMMING“ d.o.o. - Srbobran. Kotao je u eksploataciji od 2007. godine.

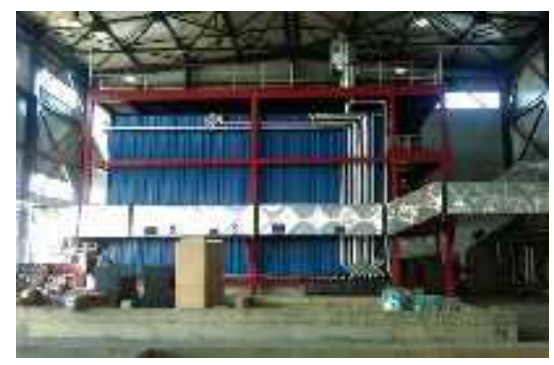

Slika 1. Izgled vrelovodnog kotla ERK - RH3O

Osnovni tehnički podaci o kotlu dati su u tabeli 1. Rad vrelovodnog kotla ERK- RH30 omogućava proizvodnju pregrejane, vrele vode, sagorevanjem mazuta preko gorionika "Saacke Bremen-GMGZ 300". Napajanje kotla demineralizovanom kotlovskom vodom vrši se preko napojnog rezervoara. Kao gorivo koristi se mazut uz dodatak aditiva (ISO PMDI 921401 A1 i Hydeo X). Vrelovodne i napojne instalacije su izolovane mineralnom vunom. 
Tabela 1 - Tehnički parametri vrelovodnog kotlovskog postrojenja ERK-RH30, JKP „Toplana Valjevo"

\begin{tabular}{|c|c|}
\hline Godina proizvodnje & 2007. \\
\hline Radna zapremina & $14,1 \mathrm{~m}^{3}$ \\
\hline $\begin{array}{l}\text { Maksimalno dozvoljena } \\
\text { temperatura }\end{array}$ & $130{ }^{\circ} \mathrm{C}$ \\
\hline $\begin{array}{l}\text { Maksimalno dozvoljen } \\
\text { nadpritisak }\end{array}$ & 16 bar \\
\hline Ispitni pritisak & 33 bar \\
\hline Zagrevna površina & $656 \mathrm{~m}^{2}$ \\
\hline Gorivo & Mazut \\
\hline Gorionik & $\begin{array}{l}\text { "Saacke Bremen - } \\
\text { GMGZ 300" }\end{array}$ \\
\hline
\end{tabular}

\section{Ispitivanja kotlovskog postrojenja metodama bez razaranja}

Ispitivanja kotlovskog postrojenja metodama bez razaranja obuhvatila su standardne postupke:

- vizuelni pregled

- merenje debljine zida ekranskih cevi

- merenje tvrdoće metala na odabranim ekranskim cevima

- detekciju korozijskih oštećenja i taloga

Vizuelni pregled vrelovodnog strmog membranskog kotla obavljen je na licu mesta i sastojao se u sagledavanju stanja unutrašnjih površina sa otvorenim svim revizionim otvorima sa plameno-dimne strane, otvorenim gorionikom, otvorenim ekonomajzerskim delom kotla i otvorenim dimnim kanalom do ventilacionog otvora. Kotao se zagreva preko gorionika sagorevanjem mazuta kome su dodati aditivi (slika 2).

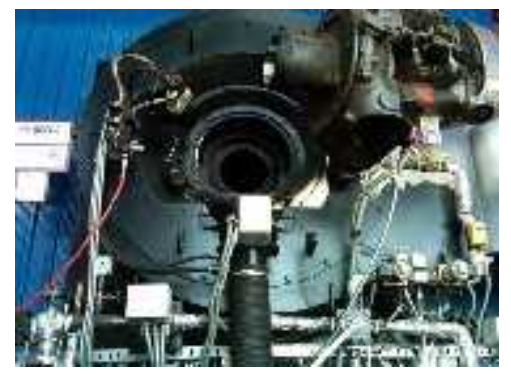

Slika 2. Gorionik

Sagorevanje je prigušeno i ne odgovara zahtevanom režimu rada gorionika. Pri sagorevanju plamen nije $\mathrm{u}$ osi kotla. Napravljen je fotografski zapis ekranskog dela kotla i ekonomajzerskog dela postrojenja u kome su primećene povećane naslage (depoziti) na cevima eko-paketa do zagušenja. Ekranski deo kotla opterećen je izrazito velikom količinom pepela na podu (slika 3.a) i sa različitom debljinom i kvalitetom depozita nastalim taloženjem produkata sagorevanja na zidovima, podu i tavanici kotla (slika 3.b).
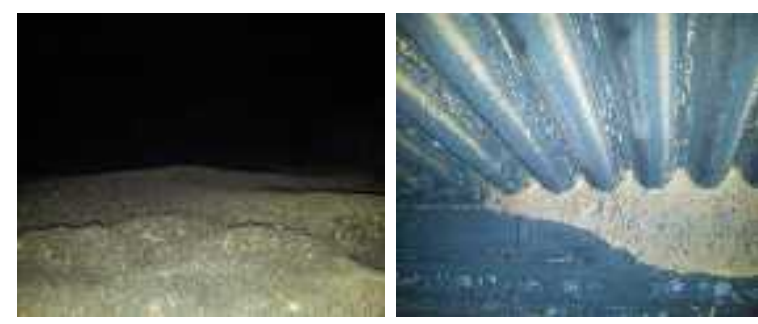

Slika 3. a) Nanosi pepela u ekranskom delu b) Membranski cevni snop

Opis depozita (šljake) u ekranskom delu kotla:

- bočni vertikalni zid sa desne strane ekranskog dela u predelu iza kolektora (gledano od gorionika) je zamašćen nesagorelim mazutom i bruniran (slika 4.a).

- bočni vertikalni zid sa desne strane ekranskog dela u predelu pre kolektora (gledano od gorionika) zaprljan je depozitom male debljine (slika 4.b).

- bočni vertikalni zid sa desne strane ekranskog dela u predelu kolektora četiri vertikalne cevi (gledano od gorionika) su potpuno čiste i suve.
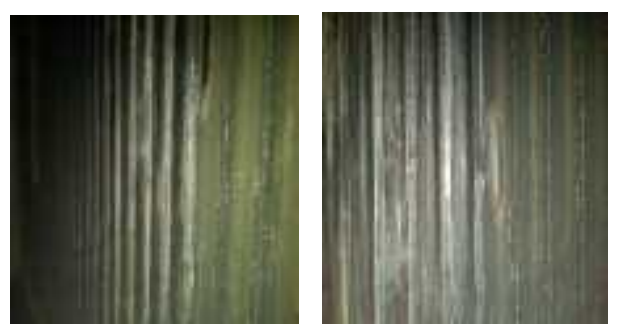

Slika 4. a) Depozit u vertikalnoj zoni ognjišta, (iza kolektora), b) Depozit u vertikalnoj zoni ognjišta, (ispred kolektora)

- bočni vertikalni zid sa leve strane i čeoni vertikalni zid (gledano od gorionika) ekranskog dela kotla opterećeni su nanosom depozita debljine $1 \mathrm{~mm}$. 
- čeoni vertikalni zid u zoni gorionika opterećen je depozitom debljine cca 2 mm (slika 5.a).

- tavanica u ravnom membranskom delu ekrana sadrži depozit debljine $4 \mathrm{~mm}$ (slika 5.b)

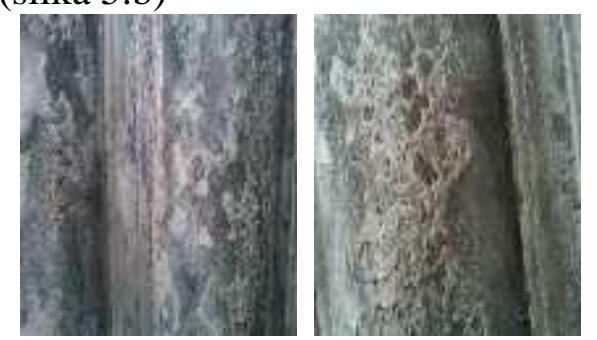

Slika 5. a) Depozit u čeonoj vertikalnoj zoni ognjišta, b) Depozit na tavanici ekranskog dela

Usled korozije i drugih uticaja radne sredine došlo je do istanjenja i oštećenja zidova ekranskog sistema zadnje komore. Istovremena pojava visokotemperaturne $\mathrm{i}$ niskotemperaturne korozije moguća je kod postrojenja koja rade neprekidno (idealni tehnički kapacitet) i koja kao radni fluid koriste pregrejanu vodenu paru. Zbog temperatura koje vladaju na površinama metala kroz koje se ostvaruje razmena toplote između dimnih gasova i radnog fluida, kod postrojenja koja kao radni fluid koriste vrelu vodu, u normalnim uslovima rada, isključena je pojava visokotemperaturne korozije. Sa druge strane, u zavisnosti od režima rada (rad sa prekidima $\mathrm{u}$ radu ili bez prekida) $\mathrm{u}$ navedenim postrojenjima su moguća dva vida niskotemperaturne korozije: tzv. coldend i dew point. Iako je sličan mehanizam odvijanja oba vida korozije sličan, termin dew point se u literaturi često odnosi na korozioni proces koji otpočinje nakon kondezovanja vodene pare iz vazduha i reakcije depozita sa kondenzatom u periodu prekida rada postrojenja. Termin cold-end korozija odnosi se na koroziju hladnih delova postrojenja koja otpočinje nakon kondenzovanja para kiselina iz dimnih gasova i njihovog deponovanja na površine metala u toku rada postrojenja. [6] Prema istraživanjima dew-point korozija nastaje kao posledica sposobnosti depozita da $\mathrm{u}$ reakciji sa kondenzovanom vodenom parom stvori sredinu u kojoj će doći do odvijanja samog procesa, dok su za nastanak cold-end korozije od značaja temperatura površine metalne cevi kao i udeli vodene pare $\mathrm{i} \mathrm{SO}_{3} \mathrm{u}$ dimnim gasovima. [8]

Vizuelnim pregledom zapaženo je prisustvo kondenzacije i ovlaženih zona sa tragovima curenja na membranskim cevima br.14 koje su sučeono zavarene. Ove cevi se nalaze vertikalno ispod gorionika u ekranskom delu kotla (slika 6.a). Vlaga u dimnim gasovima potiče od goriva (mazuta), procesa sagorevanja, propuštanja kotlovskih cevi, kao i od vlage nastale usled rada duvača gareži i gorionika. Obzirom da nisu predviđeni za transport pepela kroz ekopaket, duvači gareži ne vrše svoju funkciju samočišćenja, usled čega se njihovim radom intenzivira sabijanje čvrstih produkata sagorevanja u dimne prolaze ekonomajzera (zagrevača vode), što dovodi do zagušenja i smanjenja razmene toplote.
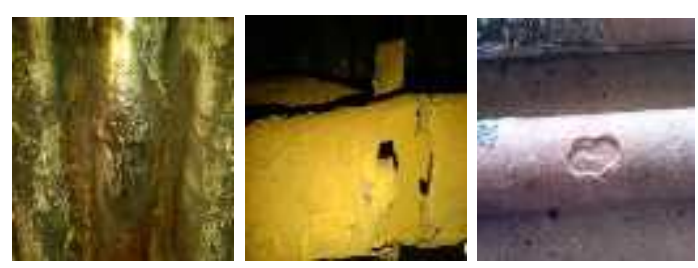

Slika 6. a) Ořtećenje zida memebranske cevi prednjeg ekranskog dela $i$ b) Izgled oštećenog duvača gareži, c) Oštećenje cevi eko-paketa

Na slici 6.b, prikazan je desni donji duvač gareži koji je oštećen usled kompresije vazduha. Određena količina pepela koja prođe kroz eko-paket puni dimne kanale do zagušenja, što stvara uslove za pregrevanje cevi ekonomajzera i dovodi do oštećenja cevi i konstrukcije eko-paketa. Pored pojave makroskopske korozije (tačkasta korozija) sa spoljašnje strane zida cevi do dubine od 2,85 mm (slika 6c), uočena je i pojava korozionog raslojavanja približne debljine $0,06 \mathrm{~mm}$. Intenzivna korozija sa spoljašnje strane cevi, nastaje kao posledica: loše konstrukcije, nepodešenosti rada gorionika ili nepotpunog sagorevanja mazuta.

Debljina zida cevi. Ispitivanje debljine zida ekranskih cevi pomoću ovog uređaja vršeno je na ukupno 18 brušenih cevi u na kritičnim cevima u dve zone u skladu sa proverama potrebe za reparacijama i zamenama cevi. $\mathrm{Za}$ 
Marković S., Gligorijević S.

otkrivanje korozijskih oštećenja i promene u dimenzijama do kojih je došlo usled dejstva korozije (pojava naslaga sa unutrašnje strane ekranske cevi) bez njenog isecanja, korišćen je ultrazvučni uređaj DM-2 sa sondama tipa DA 130/70. Navedena ispitivanja su rađena prema standardu DIN 54126. Izmerene vrednosti debljine zida cevi su u intervalu od 4,3 - 4,5mm. Sa unutrašnje strane cevi uočavaju se koroziona oštećenja i prisustvo naslaga debljine od 0,05 - 0,09mm. Međutim, sa makrosnimka vizuelne kontrole uočeno je da su naslage sa spoljašnje strane cevi mnogo veće debljine (između 10$15 \mathrm{~mm})$.

\subsection{Rezultati ispitivanja uzoraka cevi}

Hemijska analiza Ispitivane cevi su izrađene od vatroopronog čelika Č1214/1. Uporedni prikaz rezultata analize ispitivanja hemijskog sastava cevi M 1-3 i sadržaja hemijskih elemenata za čelik Č1214/1 propisanih standardom DIN 17175 dati su u tabeli 2, na osnovu čega se može zaključiti da je hemijski sastav uzoraka cevi M 1-3 zadovoljavajući. Sadržaj ugljenika u cevima je na donjoj prihvatljivoj granici.

Tabela 2 - Hemijski sastav materijala cevi $\check{C} 1214 / 1$

\begin{tabular}{|c|c|c|}
\hline $\begin{array}{c}\text { Oznaka hem. } \\
\text { elementa }\end{array}$ & DIN 17175 & $\begin{array}{l}\text { Cevi } \\
\text { M 1-3 }\end{array}$ \\
\hline $\mathrm{C}(\%)$ & $\$ 0,17$ & 0,100 \\
\hline $\mathrm{Si}(\%)$ & $0,10-0,35$ & 0,139 \\
\hline $\operatorname{Mn}(\%)$ & $0,40-0,80$ & 0,456 \\
\hline $\mathrm{P}(\%)$ & $\$ 0,040$ & 0,005 \\
\hline $\mathrm{S}(\%)$ & $\$ 0,040$ & 0,003 \\
\hline $\mathrm{Cr}(\%)$ & & 0,122 \\
\hline $\mathrm{Ni}(\%)$ & & 0,070 \\
\hline $\mathrm{Mo}(\%)$ & & 0,027 \\
\hline $\mathrm{V}(\%)$ & & 0,038 \\
\hline
\end{tabular}

Mehanička svojstva materijala Od mehaničkih svojstava ispitivana je tvrdoća cevnog sistema po Brinelu. Tvrdoća je merena na spoljnoj površini cevi iz ložišta, u okolini zavarenog spoja cevi sa membranom. Rezultati navedenog merenja i standardom propisane vrednosti tvrdoće za čelik Č1214/1 prikazani su u tabeli 3. [7]
Tabela 3 - Rezultati ispitivanja tvrdoće cevi po Brinelu $H B$

\begin{tabular}{|c|c|c|c|c|}
\hline & \multicolumn{2}{|c|}{ Merno mesto } & \multirow{20}{*}{ 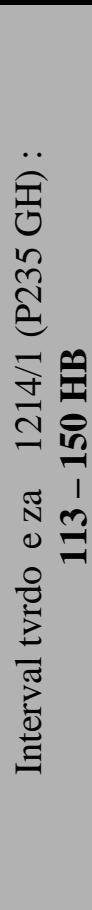 } \\
\hline & & 1 & 2 & \\
\hline \multirow{18}{*}{ 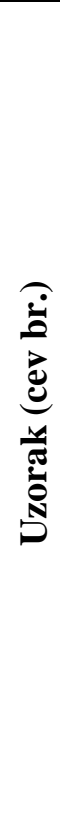 } & 1 & 131 & 124 & \\
\hline & 5 & 136 & 144 & \\
\hline & 9 & 139 & 139 & \\
\hline & 13 & 142 & 139 & \\
\hline & 17 & 140 & 150 & \\
\hline & 21 & 140 & 137 & \\
\hline & 25 & 137 & 145 & \\
\hline & 29 & 135 & 145 & \\
\hline & 33 & 142 & 140 & \\
\hline & 37 & 135 & 139 & \\
\hline & 41 & 135 & 140 & \\
\hline & 45 & 133 & 133 & \\
\hline & 49 & 136 & 132 & \\
\hline & 53 & 135 & 130 & \\
\hline & 57 & 142 & 132 & \\
\hline & 61 & 117 & 142 & \\
\hline & 65 & 142 & 126 & \\
\hline & 69 & 119 & 128 & \\
\hline
\end{tabular}

$\mathrm{Na}$ osnovu izmerenih tvrdoća spoljašnjih površina cevi po Brinelu i vrednosti tvrdoće materijala cevi Č $1214 / 1$ koje su propisane standardom prikazanih u tabeli 3, može se zaključiti da su tvrdoće cevi na nivou propisanih vrednosti.

Tabela 4 - Hemijski sastav depozita i pepela

\begin{tabular}{|c|c|c|c|c|}
\hline \multirow{2}{*}{$\begin{array}{c}\text { Izabrani } \\
\text { element }\end{array}$} & \multicolumn{4}{|c|}{$\begin{array}{c}\text { Izmerene vrednosti depozita i pepela } \\
\text { (mg/kg) }\end{array}$} \\
\cline { 2 - 5 } & $\begin{array}{c}\text { Pepeo } \\
\text { iz } \\
\text { ložišta }\end{array}$ & $\begin{array}{c}\text { Depozit } \\
\text { sa } \\
\text { tavanice } \\
\text { ekrana }\end{array}$ & $\begin{array}{c}\text { Depozit } \\
\text { sa poda } \\
\text { ekrana }\end{array}$ & $\begin{array}{c}\text { Depozit } \\
\text { ispod } \\
\text { gorionika }\end{array}$ \\
\hline $\mathrm{Fe}$ & 2881,8 & 10155 & 4862 & 7858 \\
\hline $\mathrm{Cu}$ & 102,3 & 145,8 & 113,2 & 83,65 \\
\hline $\mathrm{Mn}$ & 155,8 & 434,3 & 325,6 & 754,1 \\
\hline $\mathrm{Ni}$ & 740,3 & 135,2 & 2175 & 122,9 \\
\hline $\mathrm{Al}$ & 272,5 & 201,9 & 3.879 & 4,804 \\
\hline $\mathrm{Na}$ & 249,6 & 258,7 & 7.539 & 261,1 \\
\hline $\mathrm{Ca}$ & 820,6 & 725,3 & 1.149 & 894,3 \\
\hline $\mathrm{V}$ & 1855 & 126,6 & 6048 & 229,1 \\
\hline $\mathrm{Rh}$ & 172,7 & 340,9 & 353,4 & 82,39 \\
\hline $\begin{array}{c}\text { Sadržaj } \\
\text { karbonata } \\
{\left[10^{-3}\right]}\end{array}$ & 0.98 & 0,97 & 0 & 0 \\
\hline
\end{tabular}


Analizom depozita iz kotla (tabela 4), zapaženo je da količina pojedinih hemijskih elemenata varira $\mathrm{u}$ zavisnosti od mesta uzorkovanja, što ukazuje na nepotpuno sagorevanje mazuta i nepodešenost gorionika. Oštećenja cevi su najverovatnije bila posledica niskotemperaturnih korozionih procesa $\mathrm{u}$ toku rada $\mathrm{i} \mathrm{u}$ periodima prekida rada postrojenja.

\section{Terotehnologija kotlovskog postrojenja}

Terotehnološki poslovi i aktivnosti se mogu grupisati na osnovu četiri kriterijuma:

- prema izvoru finansiranja

- prema tehnološkoj nameni

- prema vremenu u odnosu na nastalu neispravnost

- prema načinu (karakteru) delovanja u odnosu na tehničko sredstvo.

Prema izvoru finansiranja (knjigovodstveni prilaz), vrši se podela održavanja na:

- tekuće

- investiciono (režimsko) održavanje

Rad kotlovskog postrojenja uslovljen je kvazi - rednom vezom gde otkaz jednog (ili više elemenata) ne uzrokuje otkaz sistema već nastavlja rad sa pogoršanim karakteristikama. Da bi kotlovsko postrojenje radilo prema zadatom režimu neophodno je primeniti sve raspoložive, propisane i zadate mere održavanja. Prema vremenu u odnosu na nastalu neispravnost, razlikuje se:

- program korektivnog održavanja

- program plansko-preventivnog održavanja.

Korektivni sistem održavanja karakterišu intervencije održavanja prema nastalom kvaru, odnosno poremećaju kotlovskog postrojenja. Intenzitet korektivnog održavanja direktno zavisi od otkaza elemenata svih nivoa složenosti. Intenzitet otkaza se može predvideti na osnovu praćenja ponašanja kotlovskog postrojenja u eksploataciji, na osnovu podataka o sličnim termoenergetskim postrojenjima, primenom neke od metoda za alokaciju pouzdanosti i podataka proizvođača. Plansko - preventivni sistem održavanja predstavlja skup sistematskih mera za otklanjanje uzročnika poremećaja normalnog rada postrojenja. Interpretacija ove vrste održavanja prilagođena je uslovima i potrebama kotlovskog postrojenja i obuhvata:

- proveru sigurnosne, signalne i zaporne opreme

- čišćenje i zaštitu od korozije: ekranskog dela i eko-paketa

- pregled i kontrolu parametara sagorevanja i elemenata bitnih za rad kotlovskog postrojenja

- pregled i kontrolu kolone za pripremu kotlovske vode i otprašivača

- zamenu potrebnih delova

- male opravke

- srednje opravke

- generalne opravke

Povećan sadržaj sumpora u gorivu direktno utiče na intenziviranje korozije. Izdvojena vlaga u kontaktu sa naslagama na spoljnoj površini cevi, koje su obogaćene sumporom $\left(\mathrm{SO}_{3}\right)$ formira elektrolit - sumporastu (sulfitnu) $\mathrm{H}_{2} \mathrm{SO}_{3}$ i sumpornu (sulfatnu) $\mathrm{H}_{2} \mathrm{SO}_{4}$ kiselinu vrlo niske $\mathrm{pH}$ vrednosti što rezultira vrlo intenzivnom korozijom metala ispod naslaga. U cilju sprečavanja nastanka korozionih procesa u kotlovskim postrojenjima, neophodno je smanjenje sadržaja štetnih primesa u gorivima ili njhovim prevođenjem u manje štetne oblike i/ili povećanjem $\mathrm{pH}$ vrednosti sredine.[6] Osim navedenog treba obezbediti potpuno uklanjanje naslaga sa cevi eko-paketa. Nakon čišćenja neophodno je utvrditi stepen zahvaćenosti korozijom i stepen oštećenja svih eko zona. Obzirom na postojanje korozije na unutrašnjim stranama cevi neophodna je kontrola pripreme vode, da bi se sprečilo intenziviranje korozivnih procesa. Poseban slučaj preventivnog održavanja predstavlja održavanje prema stanju. Koncepcija ovog vida se bazira na razradi metoda, tehnika i opreme za sistematsko praćenje i uvod u stanje ispravnost elemenata postrojenja (tehnička dijagnostika) i preduzimanje adekvatnih mera radi sprečavanja nastanka njihove neispravnosti. 


\subsection{Investiciono i tekuće održavanje kotlovskog postrojenja}

Tekuće održavanje odnosi se na sve poslove koji se finansiraju iz ostvarenih finansijskih sredstava postrojenja u toku tekuće godine. Tekuće održavanje karakteriše: manja složenost i obim radova, viša učestanost izvođenja radova, mogućnost izvođenja u vaneksploataciono vreme, neizmeštanje tehničkog sredstva sa mesta upotrebe, manji ukupni iznos troškova.[1] Tekuće održavanje izvode korisnici ili radnici službe održavanja. Povećavanje količina čađi i pepela u ekranskom delu kotla nastaje kao posledica: sagorevanja goriva (mazuta) različitog kvaliteta $i$ nižeg stepena opterećenja gorionika. Čak i male količine depozita smanjuju stepen iskorišćenja i skraćenje životnog veka kotla. Usled navedenog u letnjem periodu - kada kotao ne radi - treba izvršiti eliminaciju nataložene čađi i pepela. Automatsku regulaciju gorionika treba podesiti na optimalan režim rada kotlovskog postrojenja. Osim navedenog, gorionik treba podesiti u pravcu horizontalne ose ložišta da bi se obezbedilo ravnomerno zagrevanje membranskih zidova ložišta. Ventile sigurnosti treba baždariti prema radnom pritisku, zapornu i signalnu armaturu pregledati i ispitati propusnost i funkcionalnost, a merne uređaje (termometre i manometre) treba etalonirati i etiketirati markicama o ispravnosti i tačnosti opsega merenja. Sva ispitivanja podležu zakonskoj regulativi.

Investiciono održavanje odnosi se na veće radove i zahvate, pa se sredstva obezbeđuju na duži vremenski rok preko investicija. Investiciono održavanje karakteriše: veći obim i složenost poslova u odnosu na tekuce održavanje, relativno visoki troškovi, niska učestanost izvođenja, finansiranje iz troškova amortizacije. [1] Investiciono održavanje izvode isključivo radnici službe održavanja. Izrada i ugradnja novog ekopaketa (zadržana je konstrukcijska osnova ekonomajzera) doprinosi povećanju ventilacije u ekranskom delu kotla i boljem sagorevanju u ognjištu. Poboljšanja u izradi novog eko- paketa obuhvataju rasterećenja uz povećanu preciznost pri montaži, čime se oslobađaju kanali za protok dimnih gasova. Obzirom da duvači gareži ne vrše funkciju samočišćenja, pa samim tim nastaje taloženje čađi, treba ih ukloniti. Konstrukcija i montaža novog eko-paketa bi omogućila: minimalno taloženje depozita u ekonomajzeru i eko-paketu, maksimalnu prohodnost dimnih gasova kroz ekonomajzerski deo, povećanje životnog veka cevi eko-paketa, stabilnost u radu kotlovskog postrojenja, smanjenje potrošnje goriva i bolje sagorevanje, smanjenje zagađivanja životne sredine, smanjenje koncentracije reziduala u dimnim gasovima.

\section{Zaključak}

$\mathrm{U}$ radu su prikazani uzroci nastajanja oštećenja na cevima vrelovodnog kotlovskog postrojenja kao posledica depozita i uslova pod kojima je postrojenje radilo. U cilju sprečavanja korozije neophodno je obezbediti potpuno uklanjanje depozita sa cevi. Kao rezultat učestalog startovanja i zaustavljanja kotlovskog postrojenja, intenzivira se zagrevanje i hlađenje metala, što podstiče širenje prsline, odnosno nastanak loma usled zamora materijala. Kombinovani gorionik treba podesiti prema parametrima goriva koje se koristi $u$ eksploataciji, usled čega je neophodna učestala provera kvaliteta mazuta $\mathrm{i}$ određivanje tačke paljenja.

\section{Bibliografija:}

1. Klarin M, Ivanović G, Stanojević P, Terotehnologija, ICIM -Izdavački centar za industrijski menadžment, 1999, tom VI

2. Šijački Žeravčić V. i dr, Ocena integriteta cevnog sistema vrelovodnog kotla izloženog koroziji, Termotehnika br.1, godina XXXV, 2009, pp. 95-110

3. Šijački Žeravčić V. i dr, Analiza rezultata ispitivanja vrelovodnog kotla kao podloga za ocenu njegovog integriteta, Integritet i vek konstrukcija, 2007, vol.7, br.2, pp. 133-140 
4. Đurić V, Parni kotlovi - posebna poglavlja, Beogradski izdavačko grafički centar, 1973, pp.4.14

5. Đurić S, Milčić D, Smiljković M, Saniranje cevi ekranskog sistema vrelovodnog blok kotla, IMK-14 Istraživanje i razvoj, 2010, br.36

6. Gligorijević B, Jegdić B. i dr, Niskotemperaturna korozija u vrelovodnim kotlovskim postrojenjima, Termotehnika XXXV, 3-4, 2009, pp. 251-261

7. Izveštaj o ispitivanju kotla, Kontrolinženjering, 2010.

\section{Istorija rada:}

Rad primljen: 29.04.2013.

Prva revizija: 21.05.2013.

Prihvaćen: 26.05.2013. 